\title{
Four species of land snails from Costa Rica and Panama (Pulmonata: Spiraxidae)
}

\section{Fred G. Thompson}

Florida Museum of Natural History, University of Florida, Gainesville, Florida, USA 32611; fgt@flmnh.ufl.edu

\author{
Received 27-III-2009. C Corrected 21-VI-2009. Accepted 24-VII-2009.
}

\begin{abstract}
Four species of land snails are described from Costa Rica and Panama. Two are new species and two have remained poorly known since their first discovery. A fifth species from Mexico and Guatemala is illustrated for comparative purposes because it has not been figured since 1877, and previous figures of it are inadequate for comparative purposes. The Spiraxidae subfamilies and the Spiraxinae genera are redefined. Rev. Biol. Trop. 58 (1): 195-202. Epub 2010 March 01.
\end{abstract}

Key words: Spiraxidae, Mayaxis, Micromena, Miraradula, Pseudosubulina, Rectaxis, Volutaxis, land snails.

The purpose of this paper is to describe two new species of minute snails from Central America, and to provide additional information on the status of two other species. In order to place the species in the proper perspective regarding their classification, the subfamilies of the Spiraxidae, and the genera of the Spiraxinae are redefined.

Land snails of the Subfamily Spiraxinae are the most nearly ubiquitous and abundant group of land snails in the Middle America realm (Mexico, Central America and the West Indies). Over 100 species have been described from this realm. On the basis of my field experience in Middle America over the past fifty years I estimate that this is but a small fraction of the existing diversity. Almost any litter sample from there contains Spiraxinae, and frequently a dozen or more species may be present in a single litter sample. They are small-sized, and as a consequence they are seldom collected. The four species treated below are examples of this overlooked diversity.

Museum acronyms are:

UF=Florida Museum of Natural History, University of Florida, Gainesville, Florida, USA.
USNM=National Museum of Natural History, Washington, DC, USA.

MZUCR=Museo de Zoología, Universidad de Costa Rica, Costa Rica.

\section{Family Spiraxidae Baker, 1939}

This is a large family of carnivorous land snails that is confined to the neotropical realm. Over 260 species are recognized in Central America and Mexico. Historically spiraxids were treated as subfamilies within the Oleacinidae. H.B. Baker (1962) separated the Spiraxidae from the Oleacinidae on the basis of anatomical characters. The Spiraxidae includes three subfamilies. Anatomical characters are given in Baker 1939, 1941 and 1943. The subfamilies are recognized as follow.

Spiraxinae (Baker 1939) the shells are small, and slender and usually they are transparent or translucent. Occasional species have opaque shells. The columella is simple within the shell, but may be trunctated at the base of the aperture. The shell is corneous or whitish and lacks other pigmentation. The sculpture is variable, but usually includes incremental 
striations, growth threads or occasionally ribs. The central tooth of the radula is tricuspid or unicuspid. The lateral and marginal teeth are bicuspid.

Euglandininae (Baker 1941) the shells usually are medium- to large-sized ovate or elongate-ovate, and they have a truncated columella ending at the base of the aperture. Usually, the shell is opaque and bears incremental striations, ribs or growth varices, although some genera have smooth, glossy shells. The color is variable, grayish-white to brown, and may include stripes, flames or bands. The radular teeth are unicuspid.

Streptostylinae (Baker 1941) are small-to medium-sized ovate or elongate-ovate shells. The end of the columella is twisted within the aperture. Usually the shell is opaque and glossy, although some species may be strongly striate or costate. The color is variable light yellowish to dark brown, and may include stripes or a subsutural lighter zone. The radular teeth are unicuspid.

\section{Subfamily Spiraxinae (Baker 1939)}

Genera of the Spiraxinae are based primarily on soft anatomical characters and the radula (Baker 1939). Seldom are live specimens of these minute snails collected, and thus the anatomy of the vast majority of species remains unstudied. Shell traits of sculpture and columella development are useful but often are less discriminating because of convergences of characters between different genera. Historically spiraxids were grouped in a single genus Spiraxis, or in two genera, Spiraxis and Pseudosubulina (von Martens 1898, Pilsbry 1907) or in three genera, Spiraxis, Pseudosubulina and Volutaxis (Strebel \& Pfeffer 1882). Baker $(1939,1940)$ continues to recognize a single genus, Spiraxis, with six subgenera. Thompson $(1995,2008)$ elevated the subgenera to generic status on the basis of the combinations of shell, radular and soft anatomical differences.

Seven genera are now recognized. They are diagnosed as follow. Characters are taken from Baker (1939) and Thompson (1995).
Miraradula Baker, 1939. 1) Aperture with a subvertical, slightly twisted columella. 2) The protoconch with low very closely spaced growth threads with gradually widening interspaces. Lower whorls with thin riblets. 3) Spiral sculpture is absent. 4) Central tooth of radula tricuspid. 5) One hundred or more Lateral + marginal teeth. 6) Lateral and marginal teeth undifferentiated; each with two short cusps. 7) Penis with a small apical chamber. 8) Epiphallus absent. 9) Prostate shorter than uterus. 10) Vagina very short, almost absent. 11) Apparently oviparous. 12) Southeastern Mexico in the States of Puebla, Veracruz and Chiapas.

Rectaxis Baker, 1939. 1) Aperture with a fairly straight columella that is slightly oblique to the axis of the shell. 2) Protoconch with weak vertical thread-striations; teleoconch usually with distinct axial ribs. 3) Weak spiral sculpture present between the ribs on the lower whorls. 4) Central tooth of radula tricuspid. 5) Two lateral teeth have short cusps. 6) Marginal teeth 11-13; with one or both cusps long and needle-like. 7) Penis with a small apical chamber. 8) Epiphallus absent. 9) Prostate shorter than uterus. 10) Vagina very short, almost absent. 11) Oviparous. 12) Mexico south to Venezuela.

Volutaxis Strebel \& Pfeffer, 1882. 1) Columella usually twisted in the aperture and not remarkably truncate. 2) Third protoconch whorl with weak, close axial threads or riblets, which gradually assume the striate or ribbed sculpture on the following whorls. 3) Spiral sculpture absent, or when present very weak and intermittent. 4) The radula central tooth is unicuspid. 5) Lateral teeth 0-2; when present with two short cusps. 6) Marginal teeth 12-14; each has one long needle-like cusp and one shorter cusp. 7) Penis usually elongate and without heavy pilasters. 8) Without an epiphallus. 9) Uterus almost as long as prostate and shorter than free oviduct + vagina. 10) Vagina usually short. 11) Oviparous. 12) Numerous species in Mexico, Central America and the 
Greater Antilles Islands of Cuba, Jamaica and Hispaniola. Three subgenera are recognized. They are diagnosed below under Volutaxis.

Pseudosubulina Strebel \& Pfeffer, 1882. 1) Aperture usually with a definitely truncate columella. 2) Last whorl of protoconch with close, fine ribs; gradually assuming teleoconch sculpture of threads or ribs. 3) Spiral sculpture absent. 4) Radula central tooth unicuspid. 5) Two lateral teeth with short, subequal cusps. 6) Marginal teeth 9-18; with one needle-like and one short cusp. 7) Penis usually short with two internal pilasters. 8) Epiphallus present. 9) Uterus about as long as prostate, and shorter than free oviduct + vagina. 10) Vagina very short, almost obsolete. 11) Oviparous. 12) Numerous species in Mexico and Central America and with one species in Cuba.

Micromena Baker, 1939. 1) Shell minute, with a straight, very weakly truncate columella. 2) Last half whorl of protoconch closely striate. Later whorls with fine thread-riblets that are much narrower than their interspaces. 3) With continuous spiral striations. 4) Central tooth of radula unicuspid. 5) Lateral teeth absent. 6) Marginal teeth 31, outer teeth with two subequal needle-like cups. 7) Penis stout; almost filled by a verge. 8) Epiphallus present. 9) Uterus about as long as prostate and shorter than free oviduct + vagina. 10) Vagina very short. 11) Oviparous. 12) Mexico, Puebla State; one species occurs in Jamaica. Earlier, Thompson (2008) followed Baker (1939) and treated Micromena as a subgenus of Pseudosubulina. The presence of spiral sculpture and differences in the radula require that Micromena be treated as a distinct genus.

Mayaxis Thompson, 1995. 1) Shell large, up to $25 \mathrm{~mm}$ long. Aperture with a straight, vertical, truncate columella. 2) Third protoconch whorl with weakly defined low broad riblets. Teleoconch sculptured with wide low broad, rounded ribs. 3) Spiral sculpture absent. 4) Central tooth of radula vestigial, unicuspid.
5) Two lateral teeth bicuspid, cusps short. 6) Marginal teeth 13, with a long needle-like inner cup and a short outer cusp. 7) Penis with a short caecum. 8) Epiphallus about as long as penis. 9) Uterus about as long as prostate and about twice as long as free oviduct. 10) Vagina absent. 11) Oviparous. 12) Honduras and Guatemala, southeastern Mexico in the States of Chiapas and Tabasco.

Spiraxis C. B. Adams, 1850. 1) Aperture with a twisted columella. 2) Protoconch sculpture finely costulate. Teleoconch with spaced ribs. 3) Spiral sculpture absent. 4) Central tooth of radula unicuspid. 5) Lateral teeth 1 or 4 , with two short cusps. 6) Marginal teeth 6-26, with a needle-like cusp and a shot cusp. 7) Penis elongate, without heavy pilasters. 8) Penis with an epiphallus, 9) Uterus longer than prostate and much larger and longer than free oviduct + vagina. 10) Vagina short. 11) Viviparous. 12) Jamaica and Los Roques Island. Four subgenera occur in Jamaica (Baker, 1939). Another subgenus from Los Roques is questionably referred by Baker to Spiraxis.

\section{Genus Rectaxis Baker, 1926}

Spiraxis (Rectaxis) Baker, 1926; Occ. Pap. Mus. Zool., Univ. Mich., (167): 7-9.- Baker, 1939; Nautilus, 53: 10-11.- Zilch, 1959; Handbuch der Paleozoologie 6 (2): 448.

Rectaxis Baker. Thompson, 2008; Ann. checkl. bibl. land and freshwater snails Mex. Cent. Amer.: 250.

Type species: Pseudosubulina (Rectaxis) decussate Baker, 1926 (Venezuela).

The genus includes eleven previously described species (Thompson 2008) plus a new species described below. The following two species are similar to the type species of Rectaxis in their protoconch and teleoconch sculpture. Another species is referred provisionally to Rectaxis on the basis of the columellar development, but it lacks sculpture except for very fine growth threads. 


\section{Rectaxis pagodus new species}

Description (Fig. 1): The minute shell is about $2.5 \mathrm{~mm}$ long and is vitreus white in color. It is elongate conical with sides to the spire. There are 5.3-5.6 whorls, which regularly increasing in size, and are strongly shouldered and scalariform. The periphery of the whorls lies above the middle, and the whorls are strongly tapered below the periphery. The suture is very deeply impressed. The first whorl is smooth. The following whorl has fine vertical striations. The remaining whorls have strong sinuous axial ribs that are about as high as wide, and are about $1 / 4^{-1 / 2}$ as wide as their interspaces. The upper ends of the ribs weakly crenulate the suture. The ribs do not continue onto the base of the last whorl. There are 11-12 ribs/mm on the last whorl, as measured around the periphery. The last whorl has 37-39 ribs, the penultimate whorl has 34-36, and the antepenultimate has 36-37 (first numbers refer to holotype). The teleoconch whorls also have fine spiral striations that are spaced about as far apart as the width of a rib. The striations are most distinct near the base of whorls, although they are present over the entire surface. The aperture is trapezoidal in shape, being narrowed below. The outer lip is arched forward at the periphery, and is receded above and below. The columella is weakly concave.

Measurements of the holotype are: length, $2.50 \mathrm{~mm}$; width, $1.00 \mathrm{~mm}$; aperture height, $0.82 \mathrm{~mm}$; aperture width, $0.53 \mathrm{~mm}$. The single worn paratype is $2.58 \mathrm{~mm}$ in length.

Type locality: La Lola agriculture Experimental Station, $47 \mathrm{~km}$ west of Limón, Limón Prov., Costa Rica. HOLOTYPE: UF 80942; collected July 23, 1963 by Fred G. Thompson. PARATYPE: UF 80943 (1); same data as the holotype. These specimens were found in debris on a lateritic hillside in a rain forest.

Remarks: The deeply impressed suture, the scalariform whorls, and the slight terminally twisted columella immediately distinguish Rectaxis pagodus from R. canalizonalis Pilsbry,
1930. The two species are placed in Rectaxis Baker, 1926, because of their spiral sculpture, which is similar to that of the type species $R$. decussatus (Baker 1926). Rectaxis decussates differs from $R$. pagodus, as well as the following species, by its larger size, being $4.5 \mathrm{~mm}$ long, it has seven whorls, which are slightly shouldered below the deeply impressed suture. The convex whorls are rounded peripherally.

Etymology: The species name pagodus is derived from Sanskrit, referring to a building or structure such as a pagoda.

\section{Rectaxis canalizonalis (Pilsbry, 1930)}

Pseudosubulina canalizonalis (Fig. 2) Pilsbry, 1930; Proc. Acad. nat. Sci. Phila., 82: 345; pl. 29, Fig. 7 (shell).- Baker, 1963; Proc. Acad. nat. Sci. Phila., 115: 218.

Spiraxis canalizonalis (Pilsbry). Baker, 1940; Nautilus, 53: 92.

Pseudosubulina (Micromena) canalizonalis (Pilsbry). Thompson 2008: 651.

Type locality: A roadside bank Southeast of Empire, [Barro Colorado Island], Panama. The holotype apparently is lost; formerly ANSP 151350. For an unexplained reason Baker (1963) listed ANSP 151351 as the holotype. This specimen is not the one that Pilsbry described or figured. It is a dirt-encrusted specimen with a badly fractured last whorl. The specimen that Pilsbry described and figured cannot be located (Paul Callomon, personal communication).

Distribution records: PANAMA. In addition to the type locality, ruins of Old Panama City (Pilsbry 1930).

Specimens examined: PANAMA. ANSP 151351 (Baker 1963). Darien Prov.: 6.5 km West of Boca de Cope (UF 78068). COSTA RICA. Cartago Prov.: Inter-American Agricultural Institute, Turrialba (UF 212302-4 spec).

Remarks: A single specimen from Panama is referred to this species (Fig. 2) (UF 

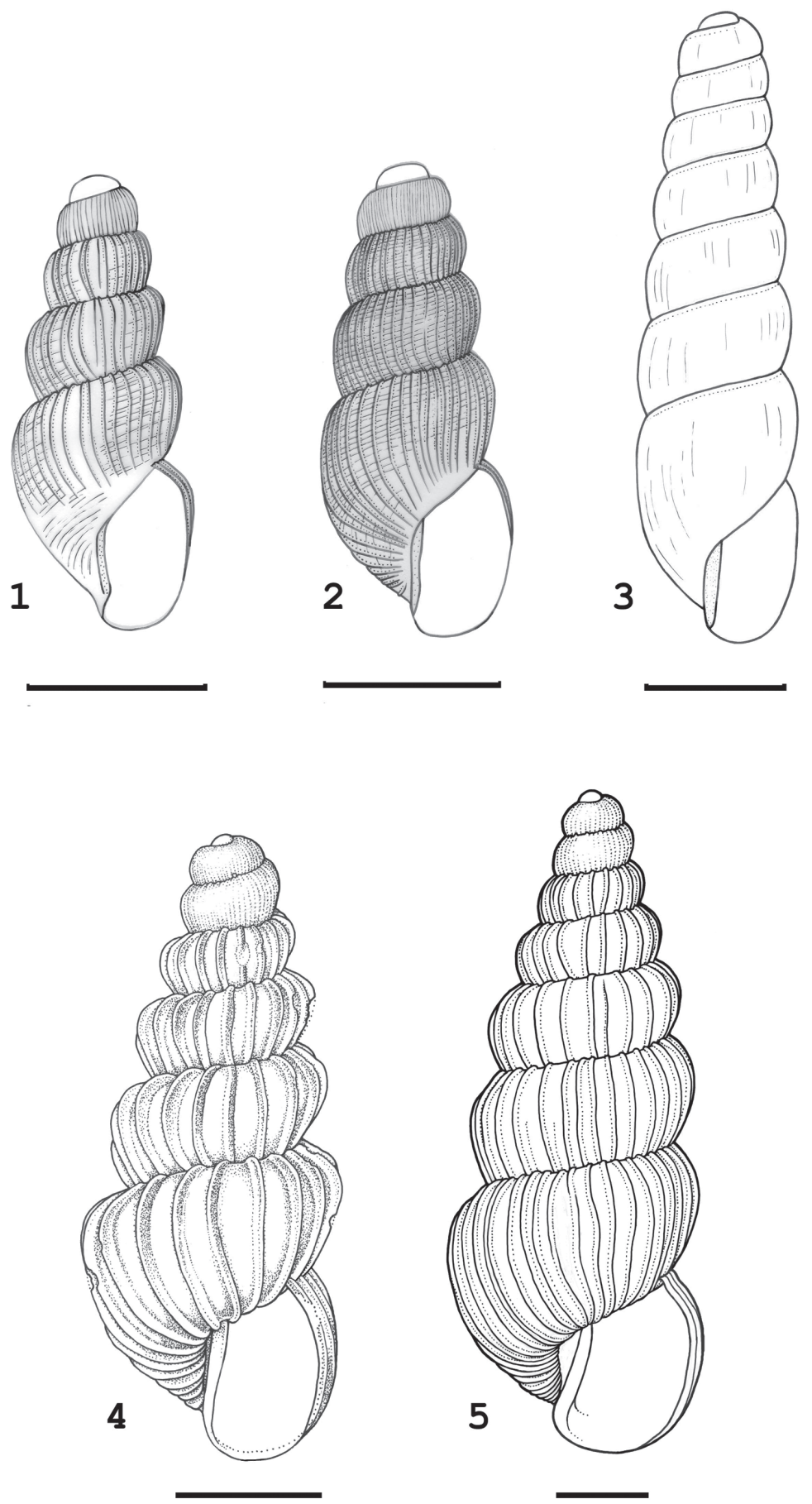

Figs. 1-5. Five species of Spiraxinae. 1. Rectaxis pagodus new species. Holotype: UF 80942. 2. Rectaxis canalizonalis (Pilsbry, 1930). UF 78068. 3. Rectaxis paulisculpta (Rehder, 1942). Holotype: USNM 526016. 4. Volutaxis eburneus new species. Holotype: UF 215408. 5. Volutaxis sulciferus sulciferus (Morelet, 1851). Mexico, Oaxaca, 9.2km NE of Valle Nacional, 250m alt. UF 77801. Scale bars equal $1 \mathrm{~mm}$. 
78068). It has five whorls, and differs from the type description by having more crowded ribs. The holotype was described as having $12 \mathrm{ribs} / \mathrm{mm}$ on the last whorl (as measured around the periphery), with 28 ribs on last whorl, 34 ribs on the penultimate whorls, and 29 ribs on the anti-penultimate whorl. The shell is $3.6 \mathrm{~mm}$ long by $1.3 \mathrm{~mm}$ wide and has 6.5 whorls (Pilsbry 1930). The specimen from Boca de Cope has $16 \mathrm{ribs} / \mathrm{mm}$ as measured along the periphery, with 40 ribs on the last whorl and 36 on the penultimate whorl. It has 5.4 whorls. The last whorl tends to be flat sided with a very deep suture, the whorls are weakly shouldered, and the specimen is $2.6 \mathrm{~mm}$ long by $1.1 \mathrm{~mm}$ wide. It appears to be a juvenile specimen with one whorl less than the holotype. In the specimen from Boca de Cope the last whorl is equivalent to the penultimate whorl in the holotype. The ribs are similarly curved in the two specimens.

The Costa Rican specimens (UF 212302) differ from the holotype by being more tapered, by having slightly concave sides to the spire, and by having a slightly larger aperture. These specimens were found under leaves and debris in a cacao grove.

\section{Rectaxis paulisculpta (Rehder, 1942)}

Spiraxis (Rectaxis) paulisculpta Rehder, 1942; Jour. Wash. Acad. Sci., 32: 350; fig. 18 (shell).

Rectaxis paulisculpta (Rehder). Thompson, 2008: 653.

This species was illustrated originally by a photograph, which does not depict important features of sculpture. It is illustrated here to clarify some of its features (Fig. 3).

The sculpture of the shell is a little different than what Rehder described. The shell is not perfectly smooth, but has rather regularly spaced very slightly raised axial threads. The threads are not readily evident because of the high gloss of the shell, but they are evident by means of transmitted light viewed through a compound scope $(100 x)$. Also of note is the relatively high first whorl.
The generic assignment of this species is problematic. The holotype (Fig. 3) lacks the characteristic spiral sculpture and axial ribs that occur on other species of the genus. The stout, straight, slightly truncate columella resembles Rectaxis more so than any other group. The columella margin of the aperture is also very finely granular

The assignment of this species to Rectaxis is doubtful, but placement in no other genus seems appropriate at this time.

\section{Genus Volutaxis Strebel \& Pfeffer, 1882}

Three subgenera are recognized.

Subgenus Volutaxis Strebel \& Pfeffer, 1882. The shell is usually larger, up to $8 \mathrm{~mm}$ long, and has a heavily sigmoid columella. The last protoconch whorl has closely spaced axial threads. The vagina is about as long as the penis. The free oviduct is about four times as long as the uterus. Nineteen previously described species are known from Mexico and Guatemala south to Costa Rica. Additional species occur in Cuba, Jamaica and Hispaniola. Type species: Bulimus sulciferus Morelet, 1851.

Subgenus Mirapex Baker, 1939. The shell is larger, up to $10 \mathrm{~mm}$ long, and has a heavily sigmoid columella. The last protoconch whorl has widely spaced ribs, but the following whorls have close threads. The vagina is almost obsolete. The free vagina is about four times as long as the uterus. A single species is recognized from Veracruz State in Mexico. Type species: Spiraxis acus enigmaticaus Baker, 1939.

Subgenus Versutaxis Baker, 1939. The shell is smaller, up to $5 \mathrm{~mm}$ long, and has a weakly twisted columella. The last protoconch whorl assumes the sculpture of the following whorls of lightly incised growth threads. The vagina is practically obsolete. The free oviduct is less than twice as long as the uterus. Seven species are recognized from the central Mexican states of Michoacan, Veracruz and Puebla. Type species: Spiraxis opeas Baker, 1939. 


\section{Volutaxis (Volutaxis) eburneus new species}

Description (Fig. 4): The shell is small for the subgenus, being slightly more than $4 \mathrm{~mm}$ long, and 0.41 times as wide as long, with scalariform, strongly shouldered whorls. The periphery lies just below the shoulders. The shell is opaque ivory white. The spire is straight-sided with regularly increasing whorls. The last whorl is 0.49 times the length of the shell. Spiral sculpture is absent. The protoconch shell consists of 2 strongly arched whorls separated by a deeply impressed suture. They are sculptured with fine, by distinct, uniformly spaced axial riblets that are about as wide as their interspaces. On the last $8^{\text {th }}$ of the second protoconch whorl the riblets become much stronger and rapidly grade into the teleoconch sculpture. The teleoconch whorls bear strong, bold ribs that are slightly higher than wide at the base, with 3-5 parallel striations in the interspaces. The ribs are highest at the periphery and decrease in height toward the lower suture. The ribs become more widely spaced with growth of the lower whorls. The $4^{\text {th }}$ whorl bears 26 ribs; the $5^{\text {th }}$ whorl has 22 , and the last whorls has 17. The aperture is almost rectangular-shaped with a slightly oblique, weakly sigmoid columella. It is 0.75 times as wide as high, and is 0.27 times the length of the shell. The thick columella is nearly straight and is slightly oblique.

Measurements in mm of the holotype (UF 215409) and a referred specimen (MZUCR 1478453) are as follow.

\begin{tabular}{lcccccccccc}
\cline { 7 - 11 } & & & & & & \multicolumn{6}{c}{ ribs } \\
Holotype & 4.28 & 2.08 & 1.76 & 1.17 & 0.88 & 26 & 22 & 17 & - & 6.0 \\
MZUCR & 4.79 & 2.33 & 1.89 & 1.32 & 1.01 & 18 & 16 & 16 & 7 & 7.3
\end{tabular}

Type locality: Hitoy Cerera Biological Reserve, La Estrella, Limón Prov., Costa Rica $\left(\left(9.733^{\circ} \mathrm{N}, 82.967^{\circ} \mathrm{W}\right), 100 \mathrm{~m}\right.$. alt. Holotype UF 215408; collected by Zaidett Barrientos, 19 November, 1993.

Referred specimens: The following records are based on specimens at the Museo de Zoologia, Universidad de Costa Rica. Formerly the mollusk collection was at the Instituto Nacional de Biologia (INBio) and retains the catalog numbers of that institution. Geographic coordinates were recorded originally in UTM units, and were converted to LatitudeLongitude units by Yolanda Camacho. COSTA RICA, Limón Prov., Hitoy Cerera Biological Reserve: Sendero Chato, 9 ${ }^{\circ} 67^{\prime} 53.78^{\prime \prime N}$, 8302'67.76”'W, 100m alt. (MZUCR 14761101 spec.); Hitoy Cerera, Sector Hitoy Cerera, $9^{\circ} 67^{\prime} 80.72^{\prime} \mathrm{N}, 8^{\circ} 02^{\prime} 40.20^{\prime \prime} \mathrm{W}, 100 \mathrm{~m}$ alt. (MZUCR 1478221-2 spec.); Hitoy Cerera, Sendero Chato, $100 \mathrm{~m}$ alt., 9 ${ }^{\circ} 67^{\prime} 53.78^{\prime \prime} \mathrm{N}$, 8302'67.76”'W, (MZUCR 1478453-3 spec.);
Hitoy Cerera, Sendero Nacho, 9 ${ }^{\circ} 67^{\prime} 53.78^{\prime \prime}$, $83^{\circ} 02^{\prime} 67.76^{\prime \prime} \mathrm{W}, 100 \mathrm{~m}$ alt. (MZUCR 1475417 2 spec.); sendero a Rio Main, $9^{\circ} 62^{\prime} 88.50^{\prime \prime} \mathrm{N}$, $83^{\circ} 00^{\prime} 89.01^{\prime \prime} \mathrm{W}, 225 \mathrm{~m}$ alt. (MZUCR 14752381 spec.).

Remarks: There is considerable variation in size and sculpture among the referred specimens. Most specimens are small juveniles consisting of four or fewer whorls. A large specimen collected along the Sendero Chato trail (MNCR 1478453) differs from the holotype by having significantly fewer, more widely spaced ribs on the whorls. Meristic data for this specimen are given along with the holotype. It differs significantly by its more widely spaced, fewer ribs on the whorls, and its moiré nearly rounded whorls that are not distinctly scalariform.

This species is similar to Volutaxis sulciferus sulciferus (Morelet, 1851) (Fig. 5) by its opaque white shell sculptured with heavy ribs. Volutaxis eburneus differs by is scalariform 
whorls, and its relatively sparser and bolder sculpture. It differs further from the latter species by having a less twisted columella and its much smaller size. Volutaxis eburneus is up to $4.28 \mathrm{~mm}$ long and has 6 whorls, whereas. $V$. sulciferus is $7.5-8.1 \mathrm{~mm}$ long with 8-8.6 whorls (Strebel \& Pfeffer, 1882: 120). Another Costa Rican snail, Volutaxis scalella (von Martens 1898), is half the length of Volutaxis eberneus, and has about 5 whorls. It appears to be based on an immature specimen. Von Martens (1898: 331) does not mention the protoconch sculpture. The species remains imperfectly known.

Etymology: The species name comes from Latin, eburneus, meaning of ivory, and alludes to the appearance of the shell.

\section{ACKNOWLEDGMENTS}

I am grateful to Gary Rosenberg (ANSP) and to Robert Hershler (USNM) for the loan of specimens in their charges. I wish to thank Paul Callomon (ANSP) for his assistance concerning the identity of the holotype of Spiraxis canalizonalis. I wish to express my gratitude to Zaidett Barrientos for assistance with field work in Costa Rica, and for many other courtesies relating to this study. I am grateful to Yolanda E. Camacho Garcia, Museo de Zoologia, Universidad de Costa Rica, for providing valuable assistance with specimens loaned from that institution. Finally, I wish to thank three anonymous reviewers, whose recommendations greatly enhanced this paper.

\section{RESUMEN}

Se describen cuatro especies de caracoles terrestres de Costa Rica y Panamá. Dos son especies nuevas y dos han permanecido poco conocidas desde su descubrimiento. Se ilustra en detalle una quinta especie de México y Guatemala, para efectos comparativos, ya que no se había ilustrado desde 1877, y sus descripciones previas no son adecuadas para una comparación. Se redefinen las subfamilias pertenecientes a Spiraxidae y el género Spiraxinae.

Palabras clave: Spiraxidae, Mayaxis, Micromena, Miraradula, Pseudosubulina, Rectaxis, Volutaxis, caracoles terrestres.

\section{REFERENCES}

Baker, H.B. 1926. The Mollusca collected by the University of Michigan-Williamson Expedition in Venezuela -IV. Occ. Pap. Mus. Zool., Univ. Mich. 167: 1-49.

Baker, H.B. 1939. A revision of Spiraxis C. B. Adams. Nautilus 53: 8-16.

Baker, H.B. 1940. Mexican Subulinidae and Spiraxinae with new species of Spiraxis. Nautilus 54: 89-94.

Baker, H.B. 1941. Outline of American Oleacininae and new species from Mexico. Nautilus 55: 51-61.

Baker, H.B. 1943. The mainland genera of American Oleacininae. Proc. Acad. Nat. Sci. Philad. 95: 1-14.

Baker, H. B. 1962. Puerto Rican HOLOPOPODES. Nautilus 75: 116-121.

Baker, H.B. 1963. Type land snails in the Academy of Natural Sciences of Philadelphia, Part II. Land Pulmonata, exclusive of North America North of Mexico. Proc. Acad. Nat. Sci. Philad.113: 191-258.

Martens, E. von. 1890-1901. Biologia Centrali-Americana. Mollusca. 1-706. British Museum of Natural History, London, England.

Pilsbry, H. A. 1907-1908. Manual of conchology: Oelacinidae, Ferussacidae. Ser. 2, 19: 1-366. Academy of Natural Sciences. Philadelphia, Pennsylvania, USA.

Pilsbry, H.A. 1930. Results of the Pinchot South Sea Expedition, II. Land mollusks of the Canal Zone, the Republic of Panama and the Cayman Islands. Proc. Acad. Nat. Sci. Philad. 82: 339-354.

Rehder, H.A. 1942. Some new land shells from Costa Rica and Panama. J. Wash. Acad. Sci. 32: 350-352.

Strebel, H. \& G. Pfeffer. 1882. Beitrag zur kenntniss der fauna mexikanischer Land- und SüsswasserConchylien. Theil V: 1-144; pls. 1-19. G. J. Herbst. Hamburg, Germany.

Thompson, F.G. 2008. An annotated checklist and bibliography of the land and freshwater snails of Mexico and Central America. (Also available: http://www.flmnh.ufl.edu/malacology/mexicocentral_america_snail_checklist/).

Zilch, A. 1959-1960. Handbuch der paleozoologie, 6 (2) Euthyneura: 4481-834. Gebrüder Borntraeger, Belin, Germany. 